\title{
Does the addition of atrial pacing to amiodarone reduce the incidence of postoperative atrial fibrillation: A pilot study
}

\author{
Jennifer Shea, MD, ${ }^{\text {a }}$ Gurpreet Sodhi, MD, ${ }^{\text {a }}$ Farzad Najam, MD, ${ }^{b}$ and Allen J. Solomon, MD, ${ }^{a}$ \\ Washington, DC
}

Atrial fibrillation is the most common postoperative complication of cardiac surgery, occurring in $\leq 40 \%$ of patients after coronary artery bypass grafting and in $>50 \%$ of patients undergoing valvular heart surgery. ${ }^{1}$ Despite efforts to identify safe and effective prophylactic strategies to reduce the incidence of postoperative atrial fibrillation, this arrhythmia remains an important source of morbidity. Thus, several pharmacologic agents have been used in the prophylaxis of postoperative atrial fibrillation, with varying degrees of success. Only $\beta$-blockers and amiodarone have been convincingly shown to decrease its incidence. ${ }^{2,3}$ However, several studies have also suggested a role for atrial pacing. ${ }^{4,5}$ The aim of the present pilot study was to evaluate whether adding atrial pacing to amiodarone could further reduce the incidence of postoperative atrial fibrillation.

\section{METHODS}

\section{Study Population}

All adult patients, who were in sinus rhythm and scheduled to undergo either coronary artery bypass grafting, valvular heart surgery, or a combined procedure, were screened for participation in the present study. Patients were excluded if they had received a class I or class III antiarrhythmic agent or had second- or third-degree heart block, a pulse $<50$ beats/min, systolic blood pressure $<100 \mathrm{~mm} \mathrm{Hg}$, severe asthma, or chronic obstructive pulmonary disease. All patients provided informed consent before surgery, in accordance with a protocol approved by the institutional review board at George Washington University.

\section{Treatment Strategies}

The patients were randomly assigned (according to the medical record number) to treatment with amiodarone or a combination of amiodarone plus atrial overdrive pacing. All treatment was begun postoperatively on arrival to the cardiac surgical intensive care unit. The patients randomized to treatment with amiodarone received oral amiodarone at a dose of $400 \mathrm{mg}$ 3 times daily for 7 days or until hospital discharge (whichever came first). Amiodarone was administered orally or by nasogastric tube within 4 hours of arrival to the intensive care unit. With shorter ventilation and intensive care unit times, it was hoped that oral amiodarone would be effective.

From the Division of Cardiology, ${ }^{a}$ Department of Medicine, and Division of Cardiac Surgery, ${ }^{\mathrm{b}}$ Department of Surgery, George Washington University Hospital, Washington, DC.

Disclosures: Allen J. Solomon reports consulting fees from BMS and Pfizer. All other authors have nothing to disclose with regard to commercial support.

Received for publication Feb 9, 2014; revisions received May 5, 2014; accepted for publication May 14, 2014; available ahead of print June 18, 2014.

Address for reprints: Allen J. Solomon, MD, Division of Cardiology, Department of Medicine, George Washington University Hospital, Room 4-420, 2150 Pennsylvania Ave, NW, Washington, DC 20037 (E-mail: asolomon@mfa.gwu.edu).

J Thorac Cardiovasc Surg 2014;148:1752-3

$0022-5223 / \$ 36.00$

Copyright (c) 2014 by The American Association for Thoracic Surgery

http://dx.doi.org/10.1016/j.jtcvs.2014.05.046
TABLE 1. Baseline characteristics

\begin{tabular}{|c|c|c|c|}
\hline Variable & $\begin{array}{c}\text { Amiodarone } \\
(\mathrm{n}=\mathbf{4 0})\end{array}$ & $\begin{array}{c}\text { Amiodarone } \\
\text { plus pacing } \\
(n=40)\end{array}$ & $\begin{array}{c}P \\
\text { value }\end{array}$ \\
\hline Male gender & 82 & 70 & .29 \\
\hline Age (y) & $62 \pm 11$ & $62 \pm 11$ & .39 \\
\hline CABG & 87.5 & 80 & .55 \\
\hline Valve surgery & 10 & 15 & .74 \\
\hline Combination surgery & 2.5 & 5 & 1.00 \\
\hline Off pump & 70 & 70 & 1.00 \\
\hline Vessels bypassed (n) & $3.7 \pm 1.2$ & $3.4 \pm 1.3$ & .64 \\
\hline HTN & 80 & 75 & .79 \\
\hline DM & 35 & 30 & .63 \\
\hline MI & 25 & 20 & .59 \\
\hline $\mathrm{CHF}$ & 0 & 5 & .49 \\
\hline Previous AF & 0 & 0 & 1.00 \\
\hline Asthma or COPD & 25 & 22.5 & 1.00 \\
\hline TIA or CVA & 10 & 7.5 & 1.00 \\
\hline Preoperative $\beta$-blocker & 55 & 70 & .25 \\
\hline $\mathrm{EF}(\%)$ & $57 \pm 10$ & $54 \pm 11$ & .60 \\
\hline
\end{tabular}

Data presented as mean \pm standard deviation or \%. $C A B G$, Coronary artery bypass graft surgery; $H T N$, hypertension; $D M$, diabetes mellitus; $M I$, myocardial infarction; $C H F$, congestive heart failure; $A F$, atrial fibrillation; $C O P D$, chronic obstructive pulmonary disease; $C V A$, cerebrovascular accident; $T I A$, transient ischemic attack; $E F$, ejection fraction.

For patients randomized to treatment with amiodarone and atrial pacing, amiodarone was administered the same as for the amiodarone only group. For atrial pacing, 2 epicardial pacing electrodes were placed on the posterolateral surface of the right atrium, using standard techniques. Pacing was initially set at 100 beats/min (adjusted upward, as needed, to maintain atrial pacing) as soon as the patient arrived in the intensive care unit and was continued for $\geq 72$ hours. Atrial pacing and sensing thresholds were evaluated every 12 hours. Pacing was continued until atrial fibrillation, discharge, or loss of capture (median, 5 days).

All patients underwent continuous electrocardiographic monitoring until hospital discharge or $\geq 7$ days after surgery. Two cardiologists reviewed all the electrocardiographic data on a daily basis.

The primary endpoint of the present study was the occurrence of atrial fibrillation lasting $>5$ minutes or for any length of time and requiring treatment. The secondary endpoint was the hospital length of stay after surgery. Management of atrial fibrillation was directed by the cardiac surgical team.

\section{Statistical Analysis}

The data were analyzed using the intention-to-treat principle. Continuous variables are summarized as the mean \pm standard deviation. Continuous variables were compared using the Student $t$ test.

\section{RESULTS}

The baseline characteristics of the study population are summarized in Table 1. The baseline characteristics were not different between the 2 groups. Of 126 consecutive 
TABLE 2. Adverse events

\begin{tabular}{lccr}
\hline \multicolumn{1}{c}{ Variable } & $\begin{array}{c}\text { Amiodarone } \\
\text { (n) }\end{array}$ & $\begin{array}{c}\text { Amiodarone } \\
\text { plus pacing (n) }\end{array}$ & $\begin{array}{c}\boldsymbol{P} \\
\text { value }\end{array}$ \\
\hline Symptomatic hypotension & 0 & 3 & .24 \\
Symptomatic bradycardia & 2 & 0 & .49 \\
$\begin{array}{l}\text { Symptomatic ventricular } \\
\quad \text { arrhythmia }\end{array}$ & 0 & 0 & 1.00 \\
Complete heart block & 0 & & \\
Acute kidney injury & 2 & 0 & 1.00 \\
Prolonged ventilation & 1 & 0 & .49 \\
Reoperation & 1 & 0 & 1.00 \\
Death & 0 & 1 & 1.00 \\
\hline
\end{tabular}

candidates, 80 subjects were randomized according to a willingness to participate (40 to each group). Of the 80 subjects, $4(10 \%)$ in each group developed postoperative atrial fibrillation. No subjects in the amiodarone plus atrial pacing group developed atrial fibrillation after pacing had been discontinued. The average length of stay was $6.0 \pm 2.2$ days for the patients treated with amiodarone and $5.9 \pm 2.9$ days for the patients treated with atrial overdrive pacing and amiodarone $(P=\mathrm{NS})$.

A total of 10 adverse events occurred during the study period (Table 2); 6 adverse events were in the amiodarone group and 4 in the combination group. One patient in the combination arm died during the study period. His death was from multisystem organ failure after he had experienced a stroke; however, he had not had any episodes of atrial fibrillation.

\section{DISCUSSION}

The major finding of the present study was that both amiodarone and the combination of atrial pacing plus amiodarone are effective and well tolerated. However, in the present pilot study, the addition of atrial pacing to amiodarone did not add to the effectiveness of amiodarone alone in reducing the incidence of postoperative atrial fibrillation. In addition, it appears that oral amiodarone can be started at surgery, without preoperative loading or intravenous therapy, without a loss of efficacy. Furthermore, amiodarone was well tolerated by the patients, with a low number of adverse events.

\section{References}

1. Leitch JW, Thomson D, Baird DK, Harris PJ. The importance of age as a predictor of atrial fibrillation and flutter after coronary artery bypass grafting. J Thorac Cardiovasc Surg. 1990;100:338-42.

2. Daoud EG, Strickberger A, Ching M, Goyal R, Deeb M, Bolling SF, et al. Preoperative amiodarone as prophylaxis against atrial fibrillation after heart surgery. N Engl J Med. 1997;337:1785-91.

3. Guarnieri T, Nolan S, Gottleib SO, Dudek A, Lowry DR. Intravenous amiodarone for the prevention of atrial fibrillation after open heart surgery: the Amiodarone in Coronary Heart (ARCH) trial. J Am Coll Cardiol. 1999;34:343-7.

4. Gerstenfeld EP, Hill MR, French SN, Rofino K, VanderSalm TJ, Mittleman RS Evaluation of right atrial and biatrial temporary pacing for the prevention of atrial fibrillation after coronary artery bypass surgery. J Am Coll Cardiol. 1999;33:1981-8.

5. Greenberg MD, Katz NM, Iuliano S, Tempestra BJ, Solomon AJ. Atrial pacing for the prevention of atrial fibrillation after cardiovascular surgery. J Am Coll Cardiol. 2000;35:1416-22.

\title{
Handmade trileaflet valved stent graft for pulmonary valve implantation
}

\author{
Ting-Wei Lin, MD, MSc, ${ }^{a}$ Jieh-Neng Wang, MD, ${ }^{\mathrm{b}, \mathrm{c}}$ Chung-Dann Kan, MD, PhD, ${ }^{\mathrm{a}, \mathrm{d}}$ and \\ Yu-Jen Yang, MD, PhD, ${ }^{\text {a,e }}$ Tainan City, Taiwan
}

\footnotetext{
From the Division of Cardiovascular Surgery, ${ }^{\mathrm{a}}$ Department of Surgery, College of Medicine, National Cheng Kung University, Tainan City, Taiwan; Division of Cardiology, ${ }^{\mathrm{b}}$ Department of Pediatrics, College of Medicine, National Cheng Kung University, Tainan City, Taiwan; Institute of Clinical Medicine, ${ }^{c}$ College of Medicine, National Cheng Kung University, Tainan City, Taiwan; Medical Device Innovation Center and Department of Biomedical Engineering, ${ }^{\mathrm{d}}$ National Cheng Kung University, Tainan City, Taiwan; and Department of Surgery, ${ }^{\mathrm{e}}$ Kuo General Hospital, Tainan City, Taiwan.

Disclosures: Authors have nothing to disclose with regard to commercial support.

Drs Chung-Dann Kan and Yu-Jen Yang contributed equally to the article.

Received for publication May 22, 2014; accepted for publication May 29, 2014; available ahead of print Aug 13, 2014.

Address for reprints: Chung-Dann Kan, MD, PhD, Division of Cardiovascular Surgery, Department of Surgery, College of Medicine, National Cheng-Kung University, 138 Sheng-Li Rd, Tainan City 70428, Taiwan (E-mail: kcd56@mail.ncku.edu.tw). or Yu-Jen Yang, MD, PhD, Department of Surgery, Kuo General Hospital, No. 22, Sec. 2, Minsheng Rd, Tainan City 70054, Taiwan (E-mail: yangyj@mail.ncku.edu.tw). J Thorac Cardiovasc Surg 2014;148:1753-5 $0022-5223 / \$ 36.00$

Copyright (c) 2014 by The American Association for Thoracic Surgery http://dx.doi.org/10.1016/j.jtcvs.2014.05.083
}

Children with complex congenital heart disease involving the right ventricular outflow tract (RVOT) usually need surgical repair at an early age. These patients might need a secondary operation for their degenerative or poor functional pulmonary regurgitations. Traditionally, redo open surgery is necessary to relieve the RVOT dysfunction, which carries high risks and morbidity. ${ }^{1}$ Bonhoeffer and colleagues ${ }^{1}$ first described the concept of a stent-mounted biological valve for a pulmonary position in 2000, which evolved into the current commercially available Melody (Medtronic Inc, Minneapolis, Minn) transcatheter pulmonary valve., However, it cannot be applied to an RVOT larger than $22 \mathrm{~mm}$ in diameter because of the size limitation. Furthermore, this device is not available in our country. Chang and $\mathrm{Chang}^{4}$ reported their strategy in treating pulmonary regurgitation after surgery for tetralogy of Fallot using 